\title{
LOCAL ACTIVE ENGAGEMENT AS AN EFFECTIVE TOOL FOR SUSTAINABLE TOURISM DEVELOPMENT: FIRST CONSIDERATIONS FROM THE EUROPEAN CULTURAL ROUTES CASE
}

\author{
SABRINA MENEGHELLO \& ERICA MINGOTTO \\ CISET (International Center of Studies on Tourism Economics), Ca' Foscari University, Italy
}

\begin{abstract}
Over the last decade, Cultural Routes (CR) of the Council of Europe (CoE) have flourished as an interesting example of cultural tourism, proposing thematic a mix of natural and cultural heritage and facilitating outdoor ways to experience sustainable tourism practices. The European programme states the importance of partnering among private and public stakeholders in defining and managing the Route as a sustainable tourism product; in fact, most of the studies on CR examine their state of development and future strategies, starting from these partnerships and their ability to reach this goal. Recently, some scholars have been investigating CR capability in creating new models of participation in heritage with shifting interest in different players, i.e. local communities and tourists turning from passive recipients to engaged actors. The paper aims to further investigate the specific role of these actors in CR tourism processes and resulting social impacts. It represents a preliminary investigation originating from the findings of a pilot study commissioned in 2016 by the European Institute of Cultural Routes (EICR), aimed at developing a measurement and quality control tool to ensure sustainability of CR, starting from a group of seven selected CR. In particular, this study investigates those findings, focusing mainly on the contribution of communities and tourists in tourism processes. Additional surveys and semistructured interviews with CR managers have been conducted to better identify forms of participation in decisions, product design, and tourism practices. Considerations about engagement effectiveness in relation to typology of actors, interactions, and specific phases of the management process, as well as observed social benefits, are among the key findings.
\end{abstract}

Keywords: sustainable tourism, European cultural routes, local engagement, social benefits.

\section{INTRODUCTION}

European Cultural Routes (CR) of the Council of Europe $(\mathrm{CoE})$ is a specific transnational programme aimed at promoting tangible and intangible heritage and activating mobility among countries. As a consequence, it aims at playing a primary role in generating positive impacts addressing sustainable development in many tourism destinations [1].

While it is evident that it is bridging a rich material and immaterial heritage with hospitality and welcoming services, the programme needs the presence of local actors and their living culture, what is not yet sufficiently explored is the weight and the effects that their active participation have in territorial processes focusing on tourism. Moreover, among the relevant subjects, tourists have been playing a more and more intense part in local dynamics [2]-[4].

Starting with the description of seven $\mathrm{CR}$ of the $\mathrm{CoE}$ according to the findings of a pilot study [5] commissioned in 2016 by the European Institute of Cultural Routes (EICR), this paper intends to further investigate the importance of local active engagement as effective tool in CR tourism processes addressing sustainable development, especially with regard to the social components of sustainability affecting people's well-being [6]. 


\section{CULTURAL ROUTES AND "LANDSCAPE TOURISM"}

In the literature, the tourism product based on cultural itineraries is typically analysed as an example of cultural tourism [7], [8]. It is recognized that in defining the nature of CR it has always been relevant the concept of "heritage". However, to better understand the meaning of the European programme for the tourism sector it may be useful to introduce concepts such as "landscape" and "landscape experience" [9]-[14]. They enrich the definition of "heritage" that, in this perspective, could be perceived not only as an expression of human culture but also of human relations with the place in which he functions [15]-[18].

The present study will, therefore, embrace the definition of "cultural landscape tourism" coined by CISET [19] as conceptual framework to analyze tourism planning and management processes of cultural routes. The aim is to focus on the specific CR of the CoE. According to the definition, "cultural landscape tourism" describes a specific expression of cultural tourism, including both the demand side, i.e. the tourist landscapes and the supply side, i.e. the tourism landscapes [18]. It does not define a single tangible or intangible heritage element but rather the whole landscape resulting from a mix of environmental, historical, socioeconomic characteristics, i.e. a kaleidoscope of cultural past and present meanings and values of a given area. The mentioned mix is variable according to the specific territorial context and identifies the proposed and perceived uniqueness of it. This definition may help in focusing on specific "tourist landscapes" characterized by the tourist search for local authenticities and practices, i.e. enjoying food productions, living minor villages events, choosing slow mobility. The importance of networks, itineraries and hubs - thus qualifying as itinerant tourism rather than sedentary - as well as the centrality of services favouring cultural exchanges with local people - ones who often are not directly part of the tourism system, i.e. farmers, artists, citizens, associations - seem to be among the most evident "tourism landscapes" describing the supply side.

In this perspective the concept of "landscape" better describes the multiple and actual territorial dynamics [20] of which those of the tourism sector are a part [21]. Moreover, this specific concept calls for a careful reflection on the role of different stakeholders, their participation [14] and influence in terms of social benefits. Therefore, the focus addresses sustainable tourism development in its social domain.

\section{CULTURAL ROUTE, LOCAL ENGAGEMENT AND SOCIAL SUSTAINABLE DEVELOPMENT}

Since the 1990s, scholars have been investigating CR of the CoE adopting different perspectives, focusing in particular on the CR as tourism product based on heritage, on the state of development and possible future strategies [22].

CR heritage conservation, tourism product and destination planning and management, networking and branding processes have turned out to be the main key research areas. In particular, most recent publications on CR heritage safeguarding focus on how to implement strategic plan for heritage route protection by the means of information technologies such as G.I.S. [23]. In terms of CR planning and management, specific investigations address to specific strategies, i.e. increasing length of stay [24] or report on visitor motivations and preferences. Concerning the subject of destination branding, researchers have been experimentally focusing on the importance of geo-visualization and texts as strategic tools to explore how the routes are perceived by tourists [25].

In the end, state of the art of the most recent contributions on this European programme leads to the conclusion that while much of this work has provided important practical management insights, it has tended to do so in ways that maintain or facilitate the legitimacy of the top-down management approach to heritage places. 
The present study is based on the awareness that recently some scholars have been in parallel investigating on the CR capability to create new models of participation, in a bottom up approach, turning local communities and tourists from passive recipients to engaged actors. From the idea that the Route is first of all an area of cultural, social and civic activities and that the investigation should focus on how Routes are understood in local communities, the work of Anna Goral [15] is remarkable for the capability to clearly address new issues. Since 2016 Goral have been moving behind the concept of Route as mix of resources to focus on the role of people, by defining CR "not only tourism products, but structures which affect and are affected by local communities" [20]. Moreover, she points out the importance of tourists together with local communities in these processes.

Moreover, literature has paid less attention, in terms of both quantitative and qualitative research, on how local empowerment of communities and tourists can be an effective tool in CR sustainable tourism development addressing social issues.

Social components of sustainability can be observed in specific areas of intervention able to impact community well-being. Some scholars define these components addressing people well-being through the following categories: "people" or "connectedness", i.e. social support, social trust, civic engagement; "place" or "liveability", i.e. emotional attachments such as a sense of belonging, cultural heritage, aesthetics and also access to job, education, housing, transport, leisure, public safety; and "power" or "equity", i.e. political voice, inclusion, diversity, equal access to local resources and opportunities [26].

The most recent tourism management literature explains why is important to focus on this specific theme and how the substantive (ends) and procedural (means) aspects defining social sustainability intertwine [27]. As far as the category of "livability" concerns, some studies describe that mediating engagement with local culture during tourism processes influences how authentic the experience is both for local people and tourists [28]; with reference to the categories of "connectedness" and "equity", some researchers underline that planning and stimulating different interactions among actors positively affects the design of significant experiences [29], bringing emotional benefits for residents [30] and tourists [3], [31], [32].

This preliminary study focuses on the weight of local active engagement as effective tool in CR tourism development addressing social sustainability. In more detail, investigation aims at understanding whether and in which stage local participation play a role in tourism planning and management processes.

The research presentation has been divided in two paragraphs. The first part (paragraph 4) discusses the main findings of a EICR pilot study for assessing sustainable development along seven selected CR of the CoE. The second part (paragraph 5) aims at demonstrating the strategic role of local engagement in defining CR not only as a tourism product but also as place of people interactions and social exchanges, i.e. a "cultural landscape laboratory".

\section{THE EICR PILOT STUDY}

\subsection{Reasons, steps and methodological approach of the pilot study}

The Council of Europe, the 70-year-old international organisation whose stated aim is to uphold human rights, democracy and the rule of law in Europe, began to promote and develop the programme devoted to Pan European Cultural Routes, during the 1980s, by establishing in particular three main objectives: (1) making European citizens aware that there is an European cultural identity; (2) preserving and enhancing the European cultural heritage; (3) supporting the development and enhancement of cultural tourism in Europe [33]-[35]. While cultural routes in Europe have long existed before the institution of the CoE programme, they 
have been recognized as key strength also for the development of local, regional and transnational tourism only in the last three decades [1], [36].

Since the launch of the Programme in 1987 with the Declaration of Santiago de Compostela, the Council of Europe described it "as an invitation to travel and to discover the rich and diverse heritage of Europe by bringing people and places together in networks of shared history and heritage". Therefore, EICR launched in 2014 a feasibility study for a system of indicators aimed at assessing CR. Five fields of actions/indicators have been selected: (1) Governance (how the partners manage the network); (2) Communication (exchange between the CR members and with the public); (3) Sustainable management; (4) Indicators of cultural action; (5) Economic impact. Great importance was paid also to tourism sustainable development along the CR, in order to ensure the economic, socio-cultural and environmental sustainability. Then, the Council of Europe co-operated with the European Commission in 2013 within the field of the development of ETIS - the European Tourism Indicator Systems promoted by the European Commission, with the scientific support of a pool of experts. ETIS, whose final version was launched in 2016, is both a management tool, that any destination can implement on a voluntary basis to take a sustainable approach to destination management, and a monitoring system, easy to use for collecting data and detailed information.

In the framework of this co-operation, some of the experts who participated in the ETIS task force, were involved in 2016 by EICR in the pilot project to adapt ETIS indicators for use by the CR, taking into account their characteristics and specificities [5]. At the invitation of the task force coordinator, one of the authors, was involved in the study and had the opportunity to participate in the implementation of some activities and in the analysis of findings. The methodological approach proposed by the pool of experts for adapting ETIS to $\mathrm{CR}$ and measure the economic, socio-cultural and environmental sustainability of the CR was based on a horizontal approach (governance model), related to the organizations responsible for the management of the Routes.

The main steps of the pilot study that took place from May to December 2016, can then be summarised as follows.

1. Adaptation of the ETIS indicators to the specificities of CR and development of a specific tool, i.e. the Governance Model Questionnaires addressed to CR managers.

2. Selection and involvement in the pilot study of seven CR for testing the tools.

3. Distribution of the Governance Model questionnaire among the organizations managing the seven CR selected.

4. Collection of questionnaires and analysis of results.

The CR involved were: (1) Transromanica - The Romanesque Routes of European Heritage; (2) Iter Vitis - Les Chemins de la Vigne en Europe; (3) Via Francigena; (4) Saint James Way - Santiago de Compostela; (5) European Routes of Jewish Heritage; (6) Route of Olive Tree; (7) Route of St. Olav Ways.

The Governance Model Questionnaire was developed in order to assess the contribution of the governance model of each CR to the economic, socio-cultural and environmental impacts in the territories along the Route. It was based around seven main themes: (1) Legal status; (2) Territorial dimension; (3) Membership typology; (4) Members communication and cooperation; (5) Main financial sources; (6) Local community involvement; (7) Main activities and specific projects in which funds are invested, in particular in terms of cultural heritage promotion, enhancement of people awareness, tourism development, promotion of sustainable and responsible tourism, social and economic development. 


\subsection{Main findings coming from the pilot study}

Some findings coming from this pilot study [5] have provided useful inputs for the specific scope of this paper. For that reason, the main results of this first analyses are presented hereafter.

1. Legal status: five $\mathrm{CR}$ are non-profit associations (Transromanica, Iter Vitis, Via Francigena, Saint James Way, European Routes of Jewish Heritage), one CR is a foundation (Route of Olive Tree) and one is a government organisation (Route of St. Olav Ways).

2. Territorial dimension: due to the transnational dimension all $\mathrm{CR}$ involve from three to more than 20 countries and from 10 to 100 main destinations.

3. Membership: in addition to public entities, all CR includes different typologies of bodies, i.e. non-profit organisations and/or private companies and/or foundations. The only exception is Saint James Way that involves public authorities only.

4. Members communication and cooperation: all CR ensure the communication and exchange among members, through meetings throughout the year (from two to six meetings) and/or a general assembly. Regarding cooperation, different actions are implemented: four CR promote joint events to stimulate the evolution of the network; four CR support destination strategies through tourism product development; six CR develop promotional and training activities.

5. Main financial sources: all CR rely on diversified sources of income, based in general on members' fee and/or EU, national and regional co-funding, and/or self-financing (merchandising, sales of good and services), and/or sponsorships and donations. In particular, five CR use EU co-funding and three use also self-financing.

6. Local community involvement: all CR directly organise or support its members in organising activities in favour of local involvement, mainly cultural events and public conferences.

7. Main activities and specific projects: CR use their funds for organising or supporting members to organise events and for investments, such as: existing buildings renovation/reuse (Iter Vitis); support to destinations and companies who put in place certification/labelling schemes (Iter Vitis and Jewish Heritage); promotion of local attractions and development of local tourism industry and/or local labour market (Transromanica, Francigena and Olive Tree); development of other economic sectors linked to tourism (St. Olav).

Another finding coming from the pilot is the identification of the following hypotheses that are directly or indirectly connected with the involvement of local communities and tourists in the CR development processes.

1. The involvement and engagement of the local community are strategic for supporting a participative process which takes into account local specificities and needs; making local residents, companies, public institutions, etc. aware of living in an area that is part of a CR; for stimulating social integration. The more active the CR organisation is in involving the local community, the greater the social benefits could be.

2. A strong cooperation among partners and with other local bodies, could support the exchange of good practices, the sharing of common strategies and actions in terms of socio-cultural growth, development of other networks and partnerships outside the CR. The level of cooperation among the members of the organisation could be considered as an input for generating social benefits. 
Due to these results it has seemed to be important to go further to a second step of the analyses and investigate more in detail the question of local engagement.

\section{THE STUDY ON LOCAL ENGAGEMENT IN CULTURAL ROUTES}

\subsection{Methodology}

Based on a multidimensional approach [37] not limited to the concepts of "stakeholders" and "networking" derived from management studies [38], [39], a questionnaire has been created and sent to all $38 \mathrm{CR}$ managing organisations [40]. The seven cases analysed in the previous research have been contacted first in order to continue the investigation with them. Since three out of seven have not replied within the specific deadline and due to the coincidence of the data collection with the beginning of the pandemic emergency, the authors have not considered appropriate to insist with the missing respondents. Therefore, they have decided to consider the whole list of CR with the aim of collecting information from the selection of those available to participate in the second part of the study.

The main steps of the study that took place from November 2019 to the beginning of March 2020, can then be described as follows:

1. Definition of the structure of a questionnaire aiming at collecting data and information about the role of local engagement in tourism processes.

2. Creation of the online version of the questionnaire [41].

3. Collection of contact information of all the $38 \mathrm{CR}$ from the European Cultural Route Official Web Site.

4. Distribution of the questionnaire among the managing organizations.

5. Collection of seven online filled questionnaires.

6. Analysis of results.

The questionnaire has been structured in six sections consisting of closed, multiple and open questions aimed at collecting data and considerations from $\mathrm{CR}$ managers about the following aspects: (a) Information on the CR from a tourist point of view, i.e. level of development, typical tourist experience, offer and demand, visitor profile; (b) Weight of specific categories of actors, i.e. local communities, tourism and cultural professionals, and operators from other economic sectors, in tourism processes. In this session it was asked to select for each category the three most relevant subjects in involvement; (c) Engagement in different phases of the process. The phases have been divided into three successive steps, each comprising different actions. The first step concerns the definition of the project objectives and strategies to achieve them (the decision-making sphere). The second phase concerns the definition and testing of the tourism experience, the so-called tourist product (the creative sphere). The third phase concerns the actual realization of the tourism experience and the practice by different audiences (the implementation sphere) with the real meeting and cultural exchange between "insiders" and "outsiders". Tourists/visitors have also been considered to assess their role throughout the process; d) Role of different types of interactions per phase: operators vs local communities (b2b), operators vs visitors/tourists (b2c), tourists vs tourists (c2c). Importance and efficiency of each specific interaction has been assessed in the final sections.

These are the respondent CR: (1) Via Francigena (the Italian case), (2) Via Francigena (the French case), (3) the Santiago de Compostela Pilgrim Routes (4) Iter Vitis, (5) the Phoenician Route, (6) the Route of St. Olav Ways, (7) the European Route of Megalithic Culture. This study has to be intended as an exploratory investigation. 
5.2 Main findings coming from the local engagement analyses

\subsubsection{Tourism indications}

The general tourism considerations collected from the seven CRs helps to contextualize the results obtained about the specific focus.

According to survey, the role of communities and tourists as active players does not emerge as a first answer but after having gone into the matter with more detailed questions. At first sight the most relevant actors indicated for the definition of tourism experiences are the private small and medium enterprises (SMEs) along the Route, generally family-based businesses including accommodation owners. In the following paragraphs it will be highlighted how the answers and the results obtained about the active role of other subjects are more articulated.

Concerning the tourist offer defining the Route it is not possible, in their opinion, to define specific sites as the most attractive ones. As stated by the Director of the Phoenicians' Project "the Route is a journey without goals, where the single attractor is not important, what is important is the sense of the Route in its complexity and atmosphere. We therefore consider the entire Route as an attraction". Some of the respondents use the term "landscape" to describe this complexity.

With regard to the characteristics of the demand, the CR generally activate a greater number of international tourists, about $60 \%$ vs $40 \%$ of domestic flows. The experience of the CR satisfies various motivations of "mature" travelers. "In the Via Francigena" explains the General Manager "spirituality, knowledge of the self and intimate research emerges. The religious reason is fixed at the $15 \%$ ". The Director of the Phoenicians' Route adds that the Route "is oriented towards experiential and creative motivation, in which the guest is involved". Other expressions used by respondents to describe motivations, tourists profile and experiences can be associated to the following four conceptual categories: (a) "time" meaning memory, "distant past" experiences, discovery of heritage related to history; (b) "space and its elements" meaning "silent" nature, legends and sagas, well-being; (c) "mobility and its expressions" referring to hiking, walking, trekking, bike, horse, slow tourism experiences; (d) "a combination of natural and anthropic attributes of the contexts", i.e. landscape, knowledge of the cultures.

\subsubsection{Different categories of actors}

Five categories of actors, i.e. stakeholders can be defined: public institutions, tourism businesses, other sectors, host communities and tourists [42]. They are groups or individuals who are associated with tourism development initiatives and therefore can affect or be affected by the decisions and activities concerning those initiatives.

The second session investigates who are different actors in the whole process.

- With regard to host communities, it emerged the relevance of cultural associations and, secondly, citizens who have interest in developing a tourism business. Citizens with focused interests (social, environmental) and related associations are quite relevant;

- Considering public and private operators, institutions are the most quoted. Accommodation sector is assessed as relevant whereas cultural private management staff and information offices are quite relevant. Only one respondent quotes as relevant the incoming travel agencies. No citation for the transport operators;

- As far as the role of other actors not directly operating in the tourism sector, farmers are the most quoted. Artisans are considered relevant. Other mentioned subjects are: schools, universities, chambers of commerce, public and private foundations, media (press, 
social, televisions, radio), nautical charters, port authorities, pilgrim associations. They are more related to the territorial specificity of single projects;

- From this first part of the survey tourists are not perceived and mentioned as local actors.

\subsubsection{Weight of actors versus phases of the process}

Concerning the engagement of the different actors in the specific phases of the process the following emerges (Fig. 1):

- the first phase of the decision-making process highlights the primary role of two types of actors. On the one hand, public institutions have a primary role in heritage safeguarding alongside the cooperation of volunteers from local communities and in organizing meetings aimed at sharing decisions supported by private operators and local communities. On the other hand, professional tourism operators have a primary role with regard to both internal and external marketing activities often with the organizational and financial support of public institutions. Private sector has a key role also in carrying out surveys and collection of data and opinions about specific tourism aspects of the CR. Locals and tourists are cited as survey respondents and therefore considered "engaged" subjects. Local communities are the most active "players" in giving voice to specific subjects, i.e. disadvantaged people facing disabilities and/or risking social exclusion asking for job positions, and needs i.e. instances to avoid land degradation, heritage banalization, social marginalization;

- as far as the definition and testing of tourism experiences is concerned, public institutions are considered the main subject in sharing heritage contents, communicating local values, organizing meetings and training sections for planning or re-assessing new proposals. The role of the public institutions is also important in indicating opportune experiences, useful data on tourist motivations and profiles. Here the weight of the local communities as supporters emerges as relevant. Their engagement concerns the indication of selected contents, places, itineraries and suppliers to be privileged for dedicated services and messages and the direct test of the experiences conceived. Finally, tourism private operators take part in planning meetings and training courses, in structuring proposals with regard to the technically confirmation of suppliers, places, itineraries and in reporting on customer preferences. Their weight is more evident in the actions of choice and sharing, in concert with public institutions, of promotional messages through the various channels;

- the third step concerning the concrete realization of the experience and the practice by different audiences sees the most relevant role for local communities. Citizens and associations act in an evident way in explaining heritage elements, telling stories and legends, providing information, animating experiences such as singing, playing, dancing, hosting at home, teaching arts and crafts. Important here is the role of tourists as well, especially in their interaction with local communities. Tourists take a decisive part in co-creating specific experiences starting from their cultural background, i.e. enriching religious rituals, culinary practices, making new light to specific heritage aspects suggesting personal interpretation, slowly discovering new landscapes, perceived as important for them. Tourist are also relevant in sharing experiences they are living through videos, photos, descriptions and comments, especially online. Public institutions have a limited role: explaining heritage aspects, welcoming and providing information are managed by authorized figures in charge, i.e. local guides. Even the role of private operators is mentioned limited to accommodation and assistance services, 
Decision making for development and governance

Defining and testing tourism experiences

Proposing and experiencing tourism practices

$$
0 \%
$$

- Public Institutions

- Cultural\&Tourism private Operators

- Local communities, Associations

Figure 1: Weight of involvement of different actors in the CR tourism definition and management process.

technical indications and solutions, and promoting contents also through videos and web channels.

As far as the analysis of the interactions between the different types of actors is concerned, it turns out that the decisive role is played by $b 2 c$ relations, meaning the dynamics between internal and external subjects. Also the frequency of this specific interaction during the whole process is also evaluated as an important condition for CR success in the tourism field.

The primary role of $b 2 c$ interactions is particularly evident both in the first decision phase of the process and in the development of tourism experiences. However, in the first phase, when sharing of choices is necessary, also b2b relations are considered relevant. In the third phase of experience implementation the presence of interactions among different actors is considered a less significant condition of process effectiveness. However, c2c interactions are here of interest and are mentioned as significant for the success of the tourist and visitors experience.

\section{DISCUSSION OF RESULTS AND FINAL CONSIDERATIONS}

The results coming from the first step of analysis raised, among other things, two central hypotheses: the level of cooperation among the members of the CR organisation could be considered as an input for generating social benefits in its territories; the more active the organisation is in involving the local community, the greater the social benefits could be.

Based on these assumptions, the second part of the analysis has investigated how effective local engagement is in CR tourism development and to what extent this engagement generates positive social effects addressing objectives of sustainability.

In the seven CR analysed cases, whereas the concomitant and continuous presence of all actors in the different stage of the tourism development process is evident, the weight of involvement varies in relation to the typology of actors and the phase of the process.

According to the seven interviewed managing organizations, CR tourism development can be effective not only thanks to a variety of actors interacting among them along the whole process but above all thanks to the active involvement of local communities. With regard to their indications, when the projects are managed only by public actors there is a risk of not implementing a proper enhancement of the destinations through tourism development.

For all the analysed cases institutions and tourism enterprises have a leading role in decision making processes ( $75 \%$ weight of involvement). Even if among actors the presence of local communities has been demonstrated to be key, it is a minority in the first decision 
making phase ( $20 \%$ weight of involvement). The case of the Prehistoric Rock Art Trails is emblematic in this sense. It counts a large number of rural areas lacking an adequate tourism offer that could be based on local farm guest houses if farmers were involved in participatory processes from the first phases.

Also designing and testing tourism products are institution driven processes but here it is more evident that their definition and implementation are only possible through a strong cooperation with local communities ( $27 \%$ weight of involvement).

Finally, local communities seem to be the most important actor in the final part of the process, i.e. in proposing and experiencing tourist practices (about $40 \%$ weight of involvement). At this stage locals have a leading role mostly in interacting with tourists who are themselves stimulated to be active actors in the co-creation of tourism experiences.

According to the survey, contribution of local communities generates positive social impacts mostly in the second and third phases. In fact, by supervising suppliers, itineraries and related narratives, citizens and associations help in selecting authentic values from the whole "landscape". Secondly, by testing and realizing tourist experiences, communities can play a relevant role in guaranteeing genuine experiences. Moreover, by creating specific proposals for tourists, local communities implement actions for safeguarding local culture, heritage and environment. As shown by the Phoenician Route case, local communities are able to revitalise crafts and specific expertise, i.e. those related to the fishing sector, as well as the correct interpretation of significant cultural expressions.

Concerning the role of tourists as active subjects, the research has shown that definition and management of $\mathrm{CR}$ is assured also by their local active engagement. Alongside the process tourists seems to become indispensable not only because they contribute in promotion with online texts, photos, videos and reviews during the experiences but above all because they are more and more engaged in co-creating parts of the tourist practices and narratives together with local actors. As stated by the Manager of the of Saint Olaf Ways, the project is an example of cultural exchanges and sharing of common values between local actors and tourists. In fact, every year more than 3,000 pilgrims and walkers go to the Saint Olaf Ways across Germany, Sweden or Netherlands and share with local communities a common desire for physical and mental well-being, sense of spirituality and faith and close connection with nature. Strengthening the roles and responsibilities of external visitors in local processes by flavouring the positive feeling of being useful and being able to contribute and take part in local life practices are among social benefits which should be further analysed.

This analysis represents a preliminary and exploratory investigation that could be further studied, first of all trying to engage in the survey also the other CR that were not available to participate in the study at that time. In addition, the set of interviews should be made more comprehensive in order to better understand if differences emerge depending on the type of Route, its level of development and the specific territorial contest. Since the focus of this research is about the engagement and active participation of internal and external subjects, it would be relevant for the analysis to involve themselves in the study, by directly interviewing residents, local operators and associations, visitors and tourists, etc. In such a way there would be the opportunity to directly collect their opinions about how they perceive their role and their involvement in the CR development; to what extent they feel part of the process; what main benefits come them from the CR.

Although implementable, the present results can be useful for researchers, stakeholders and decision-makers who need to plan, guide and monitor processes of local engagement in tourism planning and management aiming at sustainability. 


\section{REFERENCES}

[1] Murray, M. \& Graham, B., Exploring the dialectics of route-based tourism: The Camino de Santiago. Tourism Management, 18(8), pp. 513-524, 1997.

[2] Campos, A.C., Mendes, J., Oom do Valle, P. \& Scott, N., Co-creation experiences: attention and memorability. Journal of Travel \& Tourism Marketing, 33(9), pp. 1309-1336, 2016.

[3] Kim, J. \& Fesenmaier, D.R., Measuring emotions in real time: Implications for tourism experience design. Journal of Travel Research, 54(4), pp. 419-429, 2015.

[4] Pine, J.B. \& Gilmore, J.H., The Experience Economy: Work is Theatre \& Every Business A Stage, Harvard Business School Press: Boston, 1999.

[5] Study report on ETIS implementation within 7 pilot Cultural Routes of the Council of Europe. Cinzia de Marzo (EU legal advisor and senior expert on sustainable tourism and indicators) for the Council of Europe (Confidential report).

[6] Cloutier, S., Ehlenz, M.M. \& Afinowich, R., Cultivating Community Wellbeing: Guiding Principles for Research and Practice. International Journal of Community Well-Being, 2, pp. 277-299, 2019.

[7] Csapo, J., The role and importance of cultural tourism in modern tourism industry. Strategies for Tourism Industry - Micro and Macro Perspectives, eds M. Kasimoglu \& A. Handan, InTechOpen, pp. 201-232, 2012.

[8] Terzić, A., Bjeljac, Ž., Jovičić, A. \& Penjišević, I., Cultural route and ecomuseum concepts as a synergy of nature, heritage and community oriented sustainable development. European Journal of Sustainable Development, 3(2), pp. 1-16, 2014.

[9] Berti, E., Itinerari culturali del Consiglio d'Europa tra ricerca di identità e progetto di paesaggio, Firenze University Press: Firenze, 2012.

[10] Council of Europe, European Landscape Convention, 2000.

[11] Ingold, T., The temporality of the landscape. World Archaeology, 25(2), pp. 152-174, 1993.

[12] Minca, C., The tourist landscape paradox. Social \& Cultural Geography, 8(3), pp. 433-453, 2007.

[13] Terkenli, T.S., Landscapes of tourism. The Wiley-Blackwell Companion to Tourism, eds A.A. Lew, C.M. Hall \& A.M. Williams, 1st ed., John Wiley \& Sons: Oxford, pp. 282-293, 2014.

[14] Waterton, E., Whose sense of place? Reconciling archaeological perspectives with community values: Cultural landscapes in England. International Journal of Heritage Studies, 11(4), pp. 309-326, 2005.

[15] Bogacz-Wojtanowska, E. \& Góral, A., Networks or structures? Organizing cultural routes around heritage values. Humanistic Management Journal, 3, pp. 253-277, 2018.

[16] Kirshenblatt-Gimblett, B., Intangible heritage as metacultural production. Museum International, 56(1-2), pp. 52-65, 2004.

[17] Smith, L., The Uses of Heritage, Routledge: Oxford, 2006.

[18] Terkenli, T.S., Castiglioni, B. \& Cisani, M., The challenge of tourism in terraced landscapes. World Terraced Landscapes: History, Environment, Quality of Life, M. Varotto, L. Bonardi \& P. Tarolli, Environmental History, vol. 9., Springer: Cham, pp. 295-309, 2019.

[19] Meneghello, S. \& Mingotto, E., Networks of historic houses as strategic option for sustainable tourism development. The venetian villas case. International Journal of Sustainable Development and Planning, 3, pp. 197-208, 2018. 
[20] Góral, A., Cultural routes as a medium for changes in regions. Sharing Cultures, ed. S. Lira, R. Amoeda \& C. Pinheiro, vol. 2011, Green Lines Institute, pp. 719-728, 2016.

[21] Rabbiosi, C., Il territorio messo in scena. Turismo, consumi, luoghi, Mimesis, 2018.

[22] Durusoy, E., From An Ancient Road to a Cultural Route. Conservation and Management of the Road between Milas and Labraunda, Institut français d'études anatoliennes, 2014.

[23] Oikonomopoulou, E., Delegou, E.T., Sayas, J. \& Moropoulou, A., An innovative approach to the protection of cultural heritage. The case of cultural routes in Chios Island, Greece. Journal of Archaeological Science: Reports, 14, pp. 742-757, 2017.

[24] Rodríguez, X.A., Martínez-Roget, F. \& González-Murias, P., Length of stay evidence from the Santiago de Compostela. Annals of Tourism Research, 68, pp. 9-19, 2018.

[25] Jones, E., Guido, D. \& Severo, M., Towards place-based exploration of Instagram: Using co-design to develop an interdisciplinary geovisualization prototype. Journal of Spatial Information Science, 17, pp. 1-30, 2018.

[26] Atkinson, S., Bagnall, A., Corcoran, R. \& South, J., What is community wellbeing? Conceptual Review, Technical Report, 2017.

[27] Helgadóttir, G., Vilborg Einarsdóttir, A., Leah Burns, G., Póra Gunnarsdóttir, G. \& Matthíasdóttir, G.M.E., Social sustainability of tourism in Iceland: A qualitative inquiry. Scandinavian Journal of Hospitality and Tourism, 19(4-5), pp. 404-421, 2019.

[28] Zatori, A., Smith, M.K. \& Puczko, L., Experience-involvement, memorability and authenticity: The service provider's effect on tourist experience. Tourism Management, 67, pp. 111-126, 2018.

[29] Ming Ming, S. \& Wall, G., Implications of host/guest interactions for tourists-travel behaviour and experiences. Tourism, 58(1), pp. 37-50, 2010.

[30] Presenza, A., Del Chiappa, G. \& Sheehan, L., Residents' engagement and local tourism governance in maturing beach destinations. Evidence from an Italian case study. Journal of Destination Marketing and Management, 2(1), pp. 22-30, 2013.

[31] Han, C. \& Imram, R., Cultural tourism: An analysis of engagement, cultural contact, memorable tourism experience and destination loyalty. Tourism Management Perspectives, 26, pp. 153-163, 2018.

[32] Millan, C.L., Garzon, D., Navarro, D., C2C interactions creating value in the Route of Santiago. Journal of Business Research, 69(11), pp. 5448-5455, 2016.

[33] Global Report on Cultural Routes and Itineraries. Affiliate Members Report: Vol. 12, UNWTO, Madrid, 2015.

[34] Resolution CM/Res 12 on the Cultural Routes of the Council of Europe, 2007.

[35] The ICOMOS Charter on Cultural Routes, 2008.

[36] Council of Europe, Cultural Routes Management: From Theory to Practice, 2015.

[37] Ciervo, M., Un approccio geografico per una pianificazione territoriale sostenibile. Bollettino della Società Geografica Italiana, 13, pp. 559-572, 2014.

[38] Birley S., The role of networks in the entrepreneurial process. Journal of Business Venturing, 1, pp. 107-117, 1985.

[39] Freeman, R.E., Strategic Management: A Stakeholder Approach, Pitman: Boston, 1984.

[40] Online references on the $38 \mathrm{CR}$ Managing Organizations, Council of Europe. www.coe.int/en/web/cultural-routes/all-cultural-routes. Accessed on: 14 Nov. 2019.

[41] Online questionnaire developed by the authors. https://docs.google.com/forms/d/ 19nkoyBZfrmV3WKcKg0qdPKqJWTEEpya0j0RxeU12U-g/edit.

[42] Swarbrooke, J., Sustainable Tourism Management, Cabi Publishing: New York, 1999. 